\title{
Informing UK governance of resilience to climate risks: improving the local evidence-base
}

\author{
Candice Howarth $^{1}$ (D) - Sian Morse-Jones ${ }^{2}$ - Andrew Kythreotis ${ }^{3,4,5}$ (D) Katya Brooks $^{6}$. \\ Matt Lane ${ }^{7}$
}

Received: 9 March 2020 / Accepted: 4 August 2020 /Published online: 10 August 2020

(C) The Author(s) 2020

\begin{abstract}
International assessments of evidence on climate change (e.g. Intergovernmental Panel on Climate Change, IPCC) or national climate change risk assessments (e.g. UK Climate Change Risk Assessment, CCRA) do not offer a sufficiently granular perspective on climate impacts to adequately inform governance of resilience to climate risks at the local level. Using an analysis of UK decision-makers managing and responding to heatwaves and flood risks, this paper argues how more robust local evidence is needed to inform decision-making regarding adaptation options for enhancing local resilience. We identify evidence gaps and issues relating to local climate change impacts, including sources and quality of evidence used, adequacy and accessibility of evidence available, illcommunicated evidence and conflicting or misused evidence. A lack of appreciation regarding how scientific evidence and personal judgement can mutually enhance the quality of decision-making underpins all of these gaps. Additionally, we find that the majority of evidence currently used is reductively based upon socio-economic and physical characteristics of climate risks. We argue that a step change is needed in local climate resilience that moves beyond current physical and socio-economic risk characterisation to a more inclusive co-constitution of social and politically defined climate risks at the local scale that are better aligned with the local impacts felt and needs of stakeholders.
\end{abstract}

Keywords Climate risk $\cdot$ Resilience $\cdot$ Evidence $\cdot$ Communication $\cdot$ Local governance

\section{Introduction}

Evidence assessment and policy framing for national climate change adaptation (such as in the UK Climate Change Risk Assessments (CCRAs)) is often misaligned with local decisionmaking needs (Howarth et al. 2018). This results in adaptation strategies being slow to adjust

Candice Howarth

c.howarth@1se.ac.uk

Extended author information available on the last page of the article 
to the increasing importance of city-regionalism (Kythreotis et al. 2020), urban risk identification (Heidrich et al. 2013) and the opportunity for nested, multi-level approaches to governing climate resilience (Corfee-Morlot et al. 2011).

Nationally, the UK CCRA sets out the main priorities for UK climate change adaptation, shapes the direction of policy and action and facilitates practical applications of resilience. Internationally, the Intergovernmental Panel on Climate Change (IPCC) provides large assessments of evidence on the science, impacts and vulnerabilities associated with climate change. While the IPCC is recognised as a legitimate authority globally, despite a recent push for urban impacts to be given greater prominence in IPCC reports (e.g. IPCC 2018), it has been limited in framing its outputs from local perspectives. This has hindered the uptake of locally relevant evidence on climate impacts (Howarth and Painter 2016). Meanwhile, it is reported that policy actions framed by more robust local evidence can have wider international mitigation benefits (Estrada et al. 2017) and incorporating place-based cultures into local climate assessments can have broader social and environmental benefits beyond the notion of climate change (Nash et al. 2019). Likewise, literature related to climate decision-making under uncertainty has argued effective adaptation needs to move beyond optimal decision-making derived from predictive epistemologies from climate models (Thompson et al. 2016) to develop more social constructivist adaptation discourses that do not view scientific uncertainty as an obstacle to effective adaptation (Adger et al. 2009; Gottschick 2015).

This 'uncertainty' literature is important for future local adaptation governance and decision-making: it effectively allows for the lack of (scientific) knowledge about future climate change by enabling decision-makers to flexibly adapt to unseen conditions as they unfold, preventing maladaptation (Gersonius et al. 2015). However, much of this literature has been more relevant to scientific decision-making in the science 'domain' without really engaging with how such uncertainty translates into how policy stakeholders shape their adaptation 'storyline' (Shepherd et al. 2018). In this sense, CCRAs can be inconsistent for local use due to not always aligning with the needs of decision-makers (Howarth et al. 2017) and being unsuitable to inform adaptation planning (Skougaard Kaspersen and Halsnæs 2017). This highlights the extent to which scientific evidence, while highly needed, does not always fulfil decision-makers' requirements to increase resilience to (local) climate risks. This is an important (and complex) challenge to address seeing as decisions supported by climate information at different timescales tend to vary considerably (Nkiaka et al. 2019), and alignment with decision-makers and networks that are more likely to be affected by climate risks requires an understanding of their adaptive capacity, determined by place, social networks, and duration of residence (Waters and Adger 2017).

More sound and robust local evidence must build from salient, credible, and legitimate information (Cash et al. 2002) to increase climate resilience to wide-ranging and place-specific climate risks. This evidence must reflect an ability to navigate the boundaries between disciplines and understanding of knowledge needs of different stakeholders to enable them to make effective decisions (Defra 2013), acknowledging that such characteristics can be perceived differently by different actors. Effective decision-making requires the structures, communication channels, actors, and policies (e.g. governance writ large) involved in the process to be resilient and operational during and following the impact of a climate risk and sufficiently flexible to enable different interpretations, roles, and responsibilities of actors to be acquired. This paper examines this in the context of heatwaves and flooding in the UK.

Section 2 discusses how resilience to climate risks is currently informed in the UK with a particular focus on heatwaves and flooding, two of the most important climate risks facing the 
UK (CCC 2014). Section 3 presents the research methodology; Sections 4 and 5 discuss interview data on how evidence is used and produced and the adequacy of current evidence to inform resilience to heatwaves and flooding in the UK. The conclusion critically reflects on how these insights can be used to frame local governance and broader decision-making on climate change in the context of emerging and enhanced climate risks.

\section{Challenges in informing resilience to heatwaves and flooding in the UK}

\subsection{Complexity in defining and operationalising resilience}

The concept of resilience has become interdisciplinary and focused on the interrelationships between ecological and social systems and processes (Twigger-Ross et al. 2015). It is defined in different ways (Table 1) with shared elements (e.g. reducing exposure, recovery, capacity to adapt), illustrating the cross-disciplinary appeal of the concept and its context-dependent nature (Kythreotis and Bristow 2017). 'Resilience' fully entered into UK government emergency response terminology with the publication of the Civil Contingencies Act (2004), the subsequent establishment of Local Resilience Forums, and the Cabinet Office's National Strategic Framework for Community Resilience (2011) (Defra 2013).

Research points to the importance of confronting the politics and power inside the concept of 'resilience', and DfID's framework raises important questions to consider what constitutes effective resilience (White and Stirling 2012): questions such as 'resilience to what'? (considering different kinds of threats, shocks, or stresses), 'resilience of what?' (e.g. a structure of function; a community, an institutional structure or infrastructure, or the qualities of services being resilient), and 'resilience for whom?' (i.e. who is likely to benefit or who may be excluded) (Cutter 2016). Current UK government policy emphasises reactive decision-making to build resilience of wide-ranging communities, institutions, and structures, to specific climate-related and non-climate-related (e.g. terrorist attacks) shocks (Howarth and Monasterolo 2016). However, there is a need to move towards proactive decision-making and resilience-building to adapt and transform to future change (Pelling 2011). However, Pelling and Dill (2010) question the ability of governmental structures to plan in advance to effectively respond to disasters, emergencies, or extreme weather events and to support community resilience if events are uncertain and unpredicted. From the context of complex adaptive systems, Duit and Galaz (2008) identify five key characteristics for effective governance structures and resilience: (i) diversity, (ii) autonomy, (iii) interdependence, (iv) adaptability, and (v) collaboration. These characteristics demonstrate the need for strong collaboration and connections between cross-sectorial actors and institutions for better decision-making and enhancing resilience to better adapt to climate risks.

Building strategic responses to climate risks and enhancing national resilience require multi-faceted, multi-scale, dynamic, and reflexive decision-making processes (Howarth et al. 2019) to better combine responsibility for resilience and adaptation to climate change. The UK Committee on Climate Change's (CCC) 2019 'Progress in preparing for climate change' report shows that adaptation for different risks across many sectors still requires further work and specifies that responses and resilience could be improved by enhancing clarity of plans and analysing both $2{ }^{\circ} \mathrm{C}$ and $4{ }^{\circ} \mathrm{C}$ scenarios (CCC 2019). Yet, despite the local 'embeddedness' of many research institutions in towns and cities across the UK, the primary funding streams remain research councils lodged at the national level. However, while national 
Table 1 Overview of resilience definitions

Source Context Definition

\section{Cabinet Office Community} (2011)

Defra (2013) Climate change: climate resilience,
resilience of, and resilience to

DfID (2011) Community and disasters policy
The capacity of an individual, community, or system to adapt in order to sustain an acceptable level of function, structure, and identity

The ability of a social or ecological system to absorb disturbances while retaining the same basic ways of functioning and a capacity to adapt to stress and change

The ability of countries, communities, and households to manage change, by maintaining or transforming living standards in the face of shocks or stresses - such as earthquakes, drought, or violent conflict-without compromising their long-term prospects. Emerging from the context of disasters and framing resilience as a four-stage process, DfID's (2011) definition and framework for resilience encapsulate the following features:

- Context - the focus of resilience and whose resilience is being built (i.e. geographic community/place, social group, socio-economic system, environmental context/institution)

- Disturbance - the type of shock that a system needs to build resilience to cope with

- Capacity to deal with disturbance - the ability of a system or process to cope with a shock or stress depends on exposure (magnitude of the shock), sensitivity (degree to which a system will be affected by or will respond to, a given shock), and adaptive capacity

- Reaction to disturbance-with different possible outcomes from survive to transform

The capacity of a system to absorb disturbance and reorganise while undergoing change, so as to still retain essentially the same function, structure, identity, and feedbacks

A resilient community is one that takes intentional action to enhance the personal and collective capacity of its citizens and institutions to respond to the course of social, economic, and environmental change

The ability of a system and its component parts to anticipate, absorb, accommodate, or recover from the effects of a hazardous event in a timely and efficient manner, including through ensuring the preservation, restoration, or improvement of its essential basic structures and functions

The ability of individuals, communities, and states and their institutions to absorb and recover from shocks while positively adapting and transforming their structures and means for living in the face of long-term changes and uncertainty

Pitt (2007) Community and emergency, flood risk

Community and climate change
Resilience - the ability of the community, services, area, or infrastructure to withstand the consequences of an incident

Community resilience - the ability of a local community to prepare for emergencies and to respond and recover from them 
Table 1 (continued)

\begin{tabular}{lll}
\hline Source & Context & Definition \\
\hline $\begin{array}{c}\text { Twigger-Ross } \\
\text { et al. (2015) }\end{array}$ & $\begin{array}{c}\text { The ability of communities to reduce exposure to, prepare } \\
\text { for, cope with, recover better from, adapt, and } \\
\text { transform as needed, to the direct and indirect } \\
\text { consequences of climate change, where these } \\
\text { consequences can be both short-term shocks and } \\
\text { longer-term stresses }\end{array}$ \\
$\begin{array}{c}\text { UNSDR } \\
(2015)\end{array}$ & $\begin{array}{c}\text { Disasters and social, economic, and } \\
\text { environmental vulnerability } \\
\text { policy }\end{array}$ & $\begin{array}{c}\text { The capacity of a system, community, or society } \\
\text { potentially exposed to hazards to adapt by resisting or } \\
\text { changing in order to reach and maintain an acceptable } \\
\text { level of functioning and structure }\end{array}$ \\
\hline & &
\end{tabular}

action plays an important role in delivering the UK's climate targets and maximising resilience to climate impacts, local adaptation is hindered by a lack of stakeholder influence (Di Gregorio et al. 2019) as well as funding constraints that emanate from national distribution practices that are unresponsive and misaligned to specific context drivers of local adaptation needs (Sharma et al. 2014).

\subsection{Challenges in informing UK responses to heatwaves}

The factors that affect the ability of cities and people, systems, and structures to respond and adapt to high temperatures are complex and dynamic. They relate to, inter alia, quality of housing and the built environment, local urban geography, household income, employment, social networks, and perceptions of risks (Benzie 2014). Heatwaves exacerbate the heating properties of urban heat islands (De Ridder et al. 2017) with large and compact cities exacerbating these further (Zhou et al. 2017). Adverse impacts are wide-ranging across food, energy, water, environment resources, policy, businesses, transport, health and social care, and on people's mental and physical health. The 2017 CCRA estimates that summer heatwaves will become the norm by the 2040s and premature heat-related deaths will increase by a third by the 2050s (CCC 2016). Managing risks of exposure to such extreme temperatures over prolonged periods of time depends upon knowledge about how the climate system will change in the future, how populations will grow, and the future locations of populations. The latter two elements are known to increase exposure to heat, although this can occur at different rates in different regions, with further complexities emerging from the non-linear nature of increases in exposure (Harrington and Otto 2018). With growing urban populations, i.e. $70 \%$ of global population projected to live in cities by 2050 (Heilig 2012), come increased exposure to risks and greater pressures on infrastructure systems (et al. 2007). Urban governance faces an important challenge in ensuring the resilience of infrastructure and wellbeing of citizens.

There is currently no universal, cross-sectoral definition of a heatwave. In England, the Meteorological Office defines a heatwave as when a region exceeds a climatologically derived threshold for at least three consecutive days, whereas a Heat-Health Watch Alert is issued by Public Health England (PHE) when temperatures reach health and climatological derived thresholds for two consecutive days and the intervening night. This has significant implications for communication, decision-making, and shared understanding of when a heatwave occurs and responses required.

National-level guidance on health and other impacts of heatwaves will need to reflect the increasing risk and vulnerabilities of those it affects. Climate, specifically heatwave, risk 
experiences, and perceptions are predictive of the likelihood of an individual taking recommended protective action and provide insights through which guidance and responses can be better tailored and targeted. For example, although UK public perceptions of heat risk has increased (Steentjes et al. 2020), many individuals still do not perceive themselves as vulnerable (Williams et al. 2020) and demonstrate positive feelings towards past hot summers (Harley 2003).

\subsection{Challenges in informing UK responses to flooding}

Flooding is one of the main, 'direct' risks of the predicted increase in intensity and frequency of climate-induced precipitation that UK communities are likely to face in the future (Pitt 2007; ASC 2016) with estimated costs to the UK economy by 2040 at 110 billion (Johnson and McGuinness 2016) and risks posed by cascading infrastructure failures to energy, transport, water, and communication links. Longer-term stresses could also be generated, such as negative impacts on food and energy security from energy outages and loss, or pollution, of agricultural land and food crops leading to rising living costs including increases in home insurance premiums, energy bills, and food prices (Preston et al. 2014). Since 2004, there has been a shift in policy, attitude, roles, and responsibilities and a change in paradigm from one of flood resistance to resilience that now drive responses and decision-making in UK flood risk management (FRM) (Forrest et al. 2017). Multi-agency partnerships involving other LA departments, national agencies (e.g. Environment Agency), civil society, and communities proved invaluable in developing institutional structures, governance processes, and networks for building institutional resilience and linking with the wider resilience agenda (Forrest et al. 2017).

Conflicting perspectives on what 'resilience' is (Table 1), coupled with the need to confront the politics and power inside the concept, signposts a need to re-evaluate and re-assess what constitutes more effective evidence-based resilience governance. However, more empirical work is needed to explore how different governance 'actors' react to climate risks, the types of climate decision-making processes they involved in and evidence they utilise.

\section{Methodology}

This paper draws on data from stakeholder interviews to examine the place-based governance conditions needed for more robust evidence production and its subsequent use in informing decision-making processes relating to heatwaves and flooding. Semi-structured interviews were selected for the purpose of data collection to enable a flexible yet robust in-depth generation of high-quality data on complex topics such as the one explored in this paper (Young et al. 2018). Key stakeholders directly and indirectly involved in UK decision-making aimed at delivering resilience to climate change and/or climate risks were sampled from policymakers (involved in formulating policies and decisions on climate issues), practitioners (involved in implementing climate-related decision-making on the ground), and academia/ science (involved in producing climate risk evidence). Individuals were approached by direct email based on their knowledge, expertise, and experience assessed by a literature review of UK organisations and institutions, events attendance lists, and network contacts (Howarth et al. 2018). Additional participants were identified and approached by direct email following snowball sampling conducted via the initial interviewees recruited for the study. Interviews were semi-structured and explored: (i) interviewees' roles in decision-making processes, (ii) 
evidence used or useful in decision-making, and (iii) lessons learnt in responding to heatwaves and flooding (Table 2). To guarantee anonymity, interviewees were assigned individual codings according to their predefined category: policy (PO1, PO2, etc.), practitioner (PRA1, PRA2, etc.), and academic (ACA1, ACA2, etc.). Interviews were audio-recorded and transcribed. Transcripts were coded and analysed in NVivo 11 using a combination of inductive and deductive coding.

Overall, 27 useable interviews were obtained, with an even split across policy $(N=9)$, practitioners $(N=9)$, and academic/science $(N=9)$. Sections 4 and 5 present findings from these interviews and represent the views of the interviewees. Section 6 then discusses these findings in the broader context of the paper's aim to better understand how evidence is procured and applied by local stakeholders when making decisions on how to govern resilience. Interviewees were involved in five main areas of decision-making (Table 3): (i) forecasting, warning, and communicating; (ii) preparation and planning; (iii) responding; (iv) recovery; and (v) building capacity and supporting communities, land owners/managers, and partners. These processes tend to differ between different risks (e.g. heatwaves and flooding) (PO10) but can overlap, for example, 'building capacity and supporting communities and partners' typically underpinning many of the processes.

\section{Evidence used and produced}

This section considers the main types of evidence used in climate decision-making, including evidence produced by interviewees (and their organisations), with a focus on sources and adequacy of evidence. The term 'evidence' was understood by interviewees in different ways, from raw or modelled data through to rapid evidence assessments and more digested summaries.

\subsection{Sources of evidence used to inform decision-making}

A range of evidence types and sources is typically used by many of the interviewees to support decision-making processes in managing and responding to climate risks (Table 4). Most decisions are informed or underpinned by climate and meteorological data but with social and economic evidence of increasing interest to decision-makers (PO7, PR10).

Table 2 Questions included in interview protocol

\begin{tabular}{ll}
\hline Interview theme & Interview question \\
\hline Evidence access & - What type of evidence/data/information do you use to inform your decision-making in \\
- managing and responding to heatwaves and flooding? \\
- Where do you source your evidence? \\
- Do you produce evidence that ultimately informs decision-making in relation to heatwaves \\
- To what extent does the existing information/evidence available to you meet your needs in \\
decision-making in relation to heatwaves/flooding? \\
- To what extent do you think existing information/evidence available meets the needs of \\
- decision-making in relation to heatwaves and flooding? \\
Evidence use $\quad$ Have there been any instances when evidence has hindered decision-making? \\
- Can you describe any time when you felt decisions relating to heatwaves and flooding have \\
not been made on hard evidence/statistics but more on personal judgement?
\end{tabular}


Table 3 Types of climate decision-making processes interviewees are involved in

Forecasting, warning, and communicating Forecasting weather events and impacts and developing tools (AC1, AC7), for example, probability of a heatwave (AC1); issuing warnings, communicating, and engaging with stakeholders on risks (AC2, PO1, PR9); and research on how to best communicate warnings and risks. Typically, pre- and during events, but also some post-event reviews, and on-going research

Preparation and planning

Long-term strategic and short-term preparation and planning in advance of events. For example, managing land practices to reduce flood risks (PO7), bringing together key stakeholders to collaborate and coordinate on local adaptation and research activities, CCRAs (PR7), research on climate impacts for transport and energy sectors (AC2); ensuring resilience in the design of infrastructure projects (PR3); owning the severe weather plan (PR6); developing 'nature-based solutions' and 'blue/green infrastructure' to manage flood risks (PR10); and evaluating government policies and response mechanisms to heatwaves (PO4)

Responding

Mainly operational (and coordination) activities during an event. For example, putting in place response teams (PO2) and providing GIS input (PR5); tracking information and warnings from Met Office (PR9); making sure flood defences are sound (PO1) and rails are stressed for hot weather (PO8); bringing people together to share information on required management responses (PR6); coordinating responses in large-scale flooding event like Cumbria in 2015/2016 (PO3); monitoring weather stations across the transport network (PO8); and supporting local communities (PR1, PR8)

Recovery

Recovery processes typically in the immediate aftermath of an event but also longer-term processes. Examples include supporting local businesses and homeowners with clean-up and property repairs (PR8); managing the property level resilience (PLR) scheme to assist households to adapt their premises during recovery (PO3); reporting on impacts (PO1); and supporting households to get insurance following the 2015/2016 flooding event (PR1)

Building capacity and supporting communities, land owners, and partners
Activities to raise awareness, build understanding and capacity on risks, improve resilience, and support recovery and adaption. Mainly at local scale. Examples include providing advice to landowners on how to manage flood risks (PO7); building networks and local flood action groups to provide local peer-to-peer support (PR1); and promoting grants for property level protection (PR4)

This demonstrates the breadth and wealth of data and evidence available in the UK which decision-makers can readily consult. While these sources are depended upon highly, other, informal sources of evidence are also used, such as anecdotal information, people's memories of events (AC1, PR9), newspaper articles (AC1), media reports (AC9, PR8), assessments of evidence (PO4), and social media (PR5, PR8). Evidence produced by non-governmental oOrganisations (NGOs) also plays a role in highlighting vulnerability to climate risks (PR1) and internally produced evidence on modelling of climate change, impacts and weather forecasts $(\mathrm{AC} 1, \mathrm{AC} 2)$, telemetry on rivers and streams to provide data on water levels (PO1), and household surveys to inform FloodRe (PO9). 
Table 4 Types of evidence used to inform decision-making

Type of evidence $\quad$ Examples of evidence/data used

Evidence used comes from a variety of sources including government, agencies, and public bodies and from DEFRA Flood Resilience Community Pathfinder (FRCP) (PR1), CCC (PR1), Health \& Safety Executive (PR5), and the Highways Agency (PR9, PR6). Scientific evidence for forecasting data, systems, models, and weather warnings is predominantly sourced from the Met Office and the Hadley Centre (PR10), UKCP09 (PR3), the global network of weather observations and meteorological agencies, scientific papers, and satellite data. When it comes to flood data, the EA is a key source, and local government such as LLFAs also play a key role during surface flooding incidents (PO9), as well as LRFs (PR1), and Fire \& Rescue Services (PR9)

Climate/meteorological

Natural science

Social and Economic

Infrastructure and utilities

Risk analysis, rapid evidence assessments and policy appraisals

GIS and Satellite data
Climate (e.g. observations, future projections), weather observations, and forecasts (e.g. temperature, rainfall, seasonal, 5-day forecasts)

Hydrological (e.g. catchment and flood risk models, water management processes, river flows), sea levels and tidal information, ecological (e.g. species, vegetation change, habitat sensitivity), geology, topography, floodplains, land use/management (e.g. urban green space), etc.

Census and demographic (e.g. mortality rates); health; vulnerable people; property (e.g. location, number at risk of flooding); economic impact of floods (e.g. detailed data on economic impact of flood for every type of house or business (PO6)); economics of PLR approach (PO3); household data on levels of insurance, cost, premiums, excesses etc. to inform Flood Re (PO9); understanding the benefits to people from the environment (PO7); and governance systems

Evidence on infrastructure resilience (PO6) and key assets such as utilities, drains, and power cables

Flood risk maps and risk analysis information (e.g. on natural hazards and social and economic contexts); evidence to assess impact of policies (e.g. PHE reviews of the heatwave plan and take up by healthcare professionals) (PO4); appraisal of new flood defence schemes (PO9)

Spatial data (e.g. property addresses, location of vulnerable people, and day/night-time populations (PR5) and satellite data (AC5)

We are very aware though that we have tended to be a natural science-based organisation and, actually, a lot of the issues we face are more about the interaction of the natural environment with people. We are keen to do more to take account of social science evidence, also economic evidence (...) they are topics which we have been growing over the last few years. (PO7)

While evidence underpinning decision-making and responses to heatwaves and flood risks comes from a range of sources, interviewees (and the organisations they represent) also produce their own which is not always publicly available. This can be wide-ranging from forecasting data, to operational evidence and evaluation of existing evidence and tools (Table 5) and adds to the existing evidence base on which decision-makers within an organisation formulate their processes.

"We're constantly looking at all the flood risk warnings that are put out there on Twitter from the Environment Agency." (PR8).

The importance of having good structures in place to share and disseminate evidence effectively, including a range of communication channels, was also recognised such as 
Table 5 Types and examples of evidence produced

\begin{tabular}{|c|c|c|}
\hline Evidence & Description & Examples \\
\hline Science/forecasting & $\begin{array}{l}\text { Evidence base on climate change and } \\
\text { forecasting weather and impacts } \\
\text { including collection of raw } \\
\text { data/observations through to sophisti- } \\
\text { cated modelling }\end{array}$ & $\begin{array}{l}\text { - Evidence to feed into UK's CCRA (PR7) } \\
\text { - Forecasting of heatwaves to feed into PHE } \\
\text { warnings (AC1) } \\
\text { - Research on the impacts of extreme weather } \\
\text { events and how to improve warning system } \\
\text { for heatwaves (AC7) }\end{array}$ \\
\hline $\begin{array}{l}\text { Adaptation and } \\
\text { Resilience }\end{array}$ & $\begin{array}{l}\text { Evidence to support and inform decisions } \\
\text { around adaptation and building } \\
\text { resilience }\end{array}$ & $\begin{array}{l}\text { - Evidence to inform National Adaption } \\
\text { Programme, e.g. collecting temperature data } \\
\text { and socio-economic indicators of risk and } \\
\text { vulnerability (PO4) } \\
\text { - Community resilience in heatwaves, } \\
\text { emergency planning, and adaptation (AC6) } \\
\text { - Building evidence base on PLR, e.g. } \\
\text { small-scale pilot projects, evaluation of dif- } \\
\text { ferent schemes, identifying skills required } \\
\text { and projects on low cost resilience measures } \\
\text { (PO9, PO3) }\end{array}$ \\
\hline $\begin{array}{l}\text { Operational } \\
\text { decision-making }\end{array}$ & $\begin{array}{l}\text { Evidence produced or collated and } \\
\text { synthesised to support operational } \\
\text { decisions }\end{array}$ & $\begin{array}{l}\text { - Monitoring data on the condition of nature } \\
\text { sites to inform land management decisions } \\
\text { (PO7) } \\
\text { - Climate simulations for industry to } \\
\text { understand the sustainability of raw } \\
\text { ingredients and the supply chain (PR7) } \\
\text { - Collation of evidence to produce common } \\
\text { operating pictures during events }\end{array}$ \\
\hline $\begin{array}{l}\text { Evaluation of } \\
\text { policy or } \\
\text { processes }\end{array}$ & $\begin{array}{l}\text { Evidence to inform evaluation of policies } \\
\text { or processes }\end{array}$ & $\begin{array}{l}\text { - Evaluation of flood risk management systems } \\
\text { (PO9) and policies on heatwaves } \\
\text { - Retrospective analysis of incident } \\
\text { management for heat or flood events (PR6) }\end{array}$ \\
\hline Communication & $\begin{array}{l}\text { Building evidence base to inform how } \\
\text { best to communicate evidence }\end{array}$ & $\begin{array}{l}\text { - Working with EA and Met Office on design } \\
\text { and dissemination of products (AC3) } \\
\text { - Research on how to communicate flood risk } \\
\text { (AC4) and how people understand and re- } \\
\text { spond to communication about heatwaves } \\
\text { (AC9) }\end{array}$ \\
\hline
\end{tabular}

local radio, social media, and email (PR4) which can help reach broader audiences. However, it was also noted that the use of multiple channels alone does not always result in desired outcomes, for example, hot weather warnings on public transport (PO10). While there are many ways that evidence is disseminated, there is a need to ensure that different systems link up, for example, Met Office warnings and Resilience Direct (AC1). One suggestion was to enable a single output to be disseminated via multiple ways (AC1). The broad range of sources of evidence available to inform decisionmaking on climate risks reflects the growing recognition of action needed to improve resilience; however, this abundance of evidence can lead to mal-aligned methodologies, different sources of bias, and conflicting decisions even if based on the same evidence. 


\subsection{Adequacy and availability of evidence}

This section examines interviewees perception of the adequacy of evidence available to them and whether they can access it to make appropriate adaptation decisions. Overall, the evidence base on which to formulate responses to climate risks in the UK is considered to be abundant and reasonably good, though respondents argued that more and better quality evidence is needed (AC7, PO2, PR6, PR10), for example, to improve models (PR3, PR6), provide better forecasts (PR6), and ultimately give better information to decision-makers (PR3). Improvements have been made in the last decade in sharing data, although release to stakeholders remains limited within academia (AC4). Attitudes towards the adequacy of short-term weather forecasts are positive and generally found to meet needs relatively well (AC1, AC2, PO8) in particular those provided by the Met Office and EA are considered by interviewee PR 8 to have improved in accuracy in recent years. In contrast, a need for improved accuracy of longer term forecast events, such as, droughts (AC2), was recognised and 'from longer out' (PR10). Evidence on flooding, for example, is substantial, while not yet considered perfect (although defining perfection may not be possible); it is considered to have seen significant improvement to address knowledge gaps over recent years (PR4).

The rapid evidence assessments conducted on Defra's FRCP programme are considered extremely useful by PR1 for understanding the effectiveness of interventions. Datasets for managing and responding to flooding at county level are considered by PR9 to be reasonably accurate, boosted by the availability and usefulness of the EA's flood maps. The adequacy of evidence for heatwaves differs to flooding, due to the nature of this risk and difficulties in mapping out heatwaves in advance, hence having good processes in place becomes even more important (PR9). Evidence on heatwaves and flooding is regarded as less strong on impacts and vulnerability (PR7). On preparedness and planning, evidence has improved, with reasonably good horizontal coordination, though again more data is needed, particularly highresolution data (PO2), and operational responses would benefit from greater detail and certainty in forecasts (AC3). A lack of information is not always considered to constrain responses to heatwave and flooding; though more data would be helpful and existing data could be improved (PO2, PR6), it was noted that a real issue is resourcing (AC3).

“(...) I don't think, particularly for heatwaves and flooding, that the extent of the data necessarily constrains the response in any way. So, I think we're able to get enough information that we need to make decisions, although more data is always needed (...)" (PO2)

There are gaps when it comes to evidence on heatwaves: data on health impacts, for example, at what point people start to become more vulnerable because of heatwaves (PR7), and impacts on mental health and wider wellbeing (PO4). Similarly, more data is needed on the internal temperature of buildings to understand whether vulnerability increases or decreases, e.g. for homes, hospitals, care homes, and schools (PO4).

"We just don't have any consistently recorded data that tells us what's happening in the internal environment over time, so we don't know whether vulnerability is increasing or decreasing in buildings." (PO4) 
In addition, for heatwave planning, information is needed on the urban heat island effects (AC1), cool spaces (AC6), how transport networks may be affected and traffic modelling on how to quickly access hospitals in times of emergency:

“...things like roads can warp and rails can warp with the heat. (...)... Specifically about the heatwave is really access to hospitals so knowing where the congestion might be is a big one, so traffic modelling which is another beast as well." (AC1)

Lack of understanding and clarity on who the decision-makers are in relation to heatwaves makes access to evidence, or knowledge of what evidence (and where to source it) is needed, a challenge. It is not always clear to AC7, for example, who is acting on warnings, what decisions they make, and how better weather forecasting could help.

"We can issue heat warnings but who is actually acting on this warning and what decisions do they make based on those warnings?... we have never really... properly mapped the decisions that various decision-makers on this topic make and how better weather forecasting of information could actually help them in that......" (AC7)

\section{Assessing evidence usability for decision-making}

\subsection{Evidence gaps}

According to interviewees, gaps in evidence exist where evidence has not yet been collected, produced, or synthesised in an appropriate way to inform decision-making.

\subsubsection{Factors limiting access and use of data}

While an abundance of evidence is found to exist, several barriers can limit its usefulness in decision-making. Accessibility is constrained by a lack of knowledge on what exists, where and its quality (AC5, PR5), prohibitive access costs (e.g. data held by insurance companies (AC7), academic research papers (PR1)), sensitivity of releasing personal data (PR5), and a lack of interoperability between related datasets (AC8).

"So in my experience, all the information is out there..., but you come across the classic situation... if that information is down at the local authority level there's only a handful of people know about it and maintain it and there's always concern around its currency." (PR5)

Evidence can be poorly communicated, calling for better packaging (AC4) in order to translate evidence more concisely (without technical jargon) for policy use (PO9). One interviewee argued that there was an apparent disconnect between evidence producers and users. For example, the EA and Met Office warnings are seen by some decision-makers as being too risk averse, which can be costly to react to, and raise concerns at senior levels about appropriateness of responses (PO10). In such situations, human interpretation of alerts by Met Office advisors can help to contextualise them in relation to local scale impact. 
"We also tend to challenge the Met Office warnings with yellow and amber alerts. There's a high-level probability of low impact which is meaningless, frankly, (...). Well, they're raising an alert to tell us that something's going to happen but what they're telling us is actually trivial. (...) we're not going to turn off a multi-million pound transport network on the off-chance that a local road may flood." (PO10)

The production of evidence is considered to be also compounded by data limitations and trying to forecast or predict uncertain futures. Predicting longer-term events like droughts is challenging due to the inherent unpredictability of weather over timescales of several months and the need for improvements in modelling variables such as soil moisture (AC2).

Another factor limiting access to data is the fact that not all stakeholder users are part of the research process (PR7, PO1). Lövbrand (2011) argues how researchers find it difficult to include stakeholder engagement practices in the somewhat utilitarian and epistemic practice of climate modelling, while Kythreotis et al. (2019) have highlighted the uneven power relationships between citizens, scientists, and policymakers being a particular obstacle to co-production climate research. Stakeholder engagement in climate research, particularly adaptation remains a significant barrier that needs to be overcome for better decision-making to take place (Gramberger et al. 2015).

\subsubsection{Demographic, behaviour, and economic data}

Data on vulnerable people is considered critical for identifying and assessing population vulnerabilities, growing risks to properties, and where to deploy resources, but this is challenging to find (PR7). Typically, it is difficult to reach certain communities (PR1) or individuals with low literacy and low proficiency, especially those not engaged with community groups, who may be most vulnerable (AC9). Data exists in different locations (e.g. from police, fire service, and local authorities) that could be triangulated to provide a workable view but is sparsely shared (PR5).

"So there are quite a few data gaps where we would love to be able to measure certain things to help us assess vulnerability, but the data doesn't exist." (PO4)

Similarly, an important area of uncertainty identified relates to the predictive nature of people's responses to floods or heatwaves which can help better inform decision-makers on how to influence behavioural change (PR10). For heatwaves, there is a lack of understanding and clarity on who acts on a warning, what decisions are made or how better weather forecasting could help (AC7). Data on the economic implications of these events is also lacking which could help make a case for increased resilience and need for a re-targeting of resources and decision-making towards these risks.

"Where we're probably lacking is the data on the socioeconomic impact... what happens to people after they've been flooded, particularly things like mental health impact, how long people are out of their homes for, what sort of impact that's had on their livelihood and their social wellbeing and those sorts of data, so the health side is definitely where data is lacking most." (PO4) 


\subsubsection{Scientific forecasting, modelling, and local data}

Forecasting and modelling of the impacts of weather and climate risks such as heatwaves are thought to need improving. For example, detailed climate data or large-scale datasets on soil moisture are hard to come by and important for understanding antecedent conditions (PR10; AC2), and more data on drainage systems with better resolution is required (PR6). The interaction of surface water and ground water is poorly understood as the two have historically been tackled separately; research is beginning to emerge to bring this together (PR10).

"Lack of detailed climate data is a challenge, we would always like more of that. Both in terms of ambient climate information but also in terms of the kind of impact that we're trying to describe... [I]f we had better quality information then we could essentially improve our models and our calculations to give a better answer to our client." (PR3)

An array of spatial (location) data is also considered to be missing or not available in appropriate resolution as it is complex to represent local topography accurately (PO2). There is considerable demand for on-the-ground data and local knowledge to input into models; however, this is challenging as it is often not captured or quantifiable (AC1). Consulting local community groups (e.g. Flood Action Groups) has been used to identify and collate valuable local knowledge that has been lost over time (PR9) and can be a useful mechanism to compare and validate model outputs with activity and processes on the ground (PO8; PR1).

"When you're planning a particular intervention then you need to know exactly where the people are that you need to be helping, exactly where the flood boundary is, and that's very difficult to gather (...)." (PO2)

\subsection{Challenges in informing decision-making}

Interviewees were asked whether they experienced or were aware of situations where evidence had hindered decision-making in relation to managing and responding to climate risks.

\subsubsection{Timing}

The dynamic nature of climate risks is seen as requiring adaptive management and understanding that evidence evolves over time as an event approaches; in such cases, earlier indications of whether a particularly hot summer or wet winter is expected would be helpful (PR6). Though for others, the uncertainty of longer-term forecasts and inability to respond to early warnings may limit their usefulness even though in the longer term, this may be a better allocation of resources (AC3). In the context of heatwaves, there is recognition of the value of central government releasing information earlier to enable local government to plan and align communications to public needs (PR9).

\subsubsection{Accuracy, bias, and conflicting information}

Information considered to be inaccurate or imprecise, particularly forecasts, can be costly for decision-makers to use (PO8, PO10, PR8). For example, for transport networks, inaccurate or 
imprecise evidence has led to concerns regarding the credibility of future warnings, undermining trust (AC5), and getting forecasts wrong by just half a degree can lead to costly cancellation of engineering works (PO8). In some cases, the appropriateness of methodologies has been called into question, and where methods have been inappropriately applied, this has led to a lack of robust evidence (PO9). Conflicting information can create significant issues for decision-making, slowing down responses and eroding trust in warnings (AC1). Anecdotal evidence suggests that evidence shared via social media has been found to conflict with 'official' sources which may not be up-to-date (AC4, PR5). Harnessing social media presents an opportunity to improve both the accuracy and consistency of data; however, this must not conflict with official advice.

"Conflicting information is a big one. For example, why are governments not aligned or why does this website say this and this website says something slightly different? Even slightly different is a problem because then you don't know who to trust. So that is a big thing making sure that it all aligns (...)." (AC1)

There is a need to ensure evidence and guidance are joined up. For example, businesses have been found to relay different flood risk management advice to households (AC4) or situations where policy is unclear can lead to disagreements about who is responsible for risk management (PR4).

\subsubsection{Evidence misuse or unused}

There is concern from interviewees that evidence can be misused or used out of context (AC4), requiring arbitration to ensure correct interpretation and use (AC8).

"I do worry that we practitioners get hold of one tool and that gets circulated as kind of one version of the truth and if there are errors or that model was written for different purposes and it is used out of context, we are not maybe using the best available evidence."(AC4)

Alongside this, there is an ongoing challenge in ensuring that evidence is used and translated into practice ( $\mathrm{PO} 3, \mathrm{AC} 4)$, building effective dissemination (PO3), and incorporating more robust social science evidence, which is often seen as a weak or inaccurate (AC4).

"Certainly with PLR there was a certain element of people not reading each other's research. Which is why we did the REA to try and bring all this together and form a baseline...for any future work that they do in this area. One of the problems is how we transfer that research work into the public domain so it becomes action. And one of the things that all of our projects tend to have built into them is a strong dissemination activity." (PO3)

\subsection{The inevitable need for personal judgement}

While a large proportion of decisions related to heatwaves and flooding are based on evidence, interviewees noted that at times these had not always been made on hard evidence but more on 
personal judgement. Judgement-based decisions are inevitable and particularly pertinent for appropriate climate strategy-making because they additionally utilise the broader scientific evidence base (e.g. IPCC regional projections) to build more nuanced insights of adaptation in the local context, which evidence-based judgements alone cannot take account of (Thompson et al. 2016). Judgement-based decision-making is seen by some as omnipresent in emergency situations (AC3, PR6) and felt by some to happen "all the time" (PR7), though certain circumstances were seen to increase the likelihood in particular where evidence is lacking, incomplete (e.g. AC3, AC6; PR1).

"I think by their nature in any sort of emergency you haven't got a full set of informed evidence and there is always some judgement involved in that." (PR6)

Other examples included where a lack of cohesion exists between flood risk management roles and objectives, people are required to exercise more judgement in decisions (AC4). Similarly, while issuing weather warnings is based on the best available information, judgement is inevitably required to form a complete picture (AC7). With more research, this will improve, but the complexity of the human system and nature and the limitations and uncertainties associated with building evidence mean it will never be possible to provide a complete and final answer. The selection of and weighing up of evidence, for use in decision-making, is in itself a subjective judgement process (AC5, PR1). As one interviewee put it, decisions require a mix of evidence, experience, and judgement to produce so called "evidence-informed" decisions (AC3).

"I mean many, many decisions have to be taken in that kind of way because there isn't always evidence." (AC6)

The appropriateness of using judgement depends on specific circumstances, for example, where data cannot be trusted and is unreliable or inaccurate (PR9) and it was felt that overall, expert judgement can be invaluable in situations of high uncertainty (PO6).

“... expert judgment I think is valuable because there are areas where you have uncertainty so, (...) if you have lots of different scenarios then you do take some expert judgment to know whether it really does look like a certain scenario is going to go forward although you have to plan for all scenarios, you take that expert judgment I think this is the way it's going to go forward" (PO6)

While we did not explicitly explore interviewees' perceptions on who are the 'experts' doing the judging, in general, a wide range of sources of 'experts' or 'expertise' were referred to by interviewees, suggesting there is no specific expert on local resilience. Examples included flood forecasters (PO6); government agencies such as PHE, EA, Environmental Health, and local government (PR6); practice (PO7); GIS experts (PR5); scientific regulators (PO7); 'local' experts with knowledge on the ground (PR1, PO7) of assets and catchments (PO7); experts from within organisations (PR6); and from outside (PO7) and groups that have been peerreviewed (PR3).

It was widely thought by interviewees that decision-making can be strengthened by using both judgement and evidence. The complexity of many decisions means evidence alone may not provide the answer as it depends on specific objectives and weighing up different factors and concerns; hence, evidence-informed judgement is often the best approach (PO7). Experience and knowledge, whether held by experts or non-expert, can also add considerable value 
to decision-making (AC3, AC4, AC6, PO1, PO7, PR9) and is referred to, interchangeably, as "experiential kind of evidence" (AC4), "experts of experience", or "experts by experience" (AC6). An important distinction exists between decisions based on 'personal reasons', which may be political in nature as opposed to 'personal judgement' - the latter reflecting experience and knowledge and therefore seen as beneficial to the process (AC6).

"I think even in issuing a flood warning there is always a bit of just relying on your expertise, I don't think it can be completely mechanistic. (...) people's expertise in bringing and assimilating a lot of information together and deciding whether it is sensible to issue a flood warning (...) we can't do that in just a tool I don't think." (AC4)

"Yes, there are some occasions when experience does bring in a lot of help to be able to make the right decision as to how you're going to respond to an incident." (PR9)

It is also noted that while institutional preference is often for evidence-based decisions, overreliance can be dangerous, since information is imperfect, and in the absence of information, decisions can be delayed (PO1). Consequently, there is potentially a need to review how and where expert-based judgement can be appropriately included in decision-making both to harness and bound its use.

“(...) in emergency flooding or emergency management field that I come from you can't always have the data, sometimes you've just got to make a decision based on what you have in front of you and it may not be perfect so not being comfortable with making a decision on less than perfect information is really important." (PO1)

"use hard evidence as much possible and whatever's there but if we are objective to that extent, did that create inequalities and should we draw in that evidence or not, so, it's one we haven't bottomed out yet to be honest. So, yes, I think that's probably one of the areas that's quite hard." (PO6)

Political drivers were reported to be behind some judgement-based decisions - for some interviewees, this was too sensitive an issue to expand on. Of concern is where politically sensitive issues intersect with a lack of integrated policy, which can lead to at best a nuanced interpretation of the evidence or at worst politically motivated disregard of the evidence base (PO4). Such decisions can have serious consequences where risks are not effectively managed, and poor practice is locked in, storing up problems for the future (PO4). Systematic biases are evident in the way some decisions are made which can be self-reinforcing, for example, where the more investment an area attracts the more reason to protect it and the opposite effect for unprotected areas (PR3). Judgement-based decisions can be seen as lacking 'back-up' or justification in the event of poor outcomes, which could decrease trust of decision-making processes (AC1), and delays to decision-making may occur where evidence and experience do not align (PR9).

"Sometimes the data does not correlate to the experience and that can cause delays in making decisions, because you've got to weigh it up very carefully and obviously as an emergency responder, we've got to ensure that we consider all things and then document 
the decision making process as well, why we took a specific decision based on the information that we had at the time." (PR9)

Judgement-based decisions may fail to adequately consider wider downstream consequences (AC4) and yield inconsistent approaches such that processes become ad hoc (AC5) potentially amplifying issues associated with already a siloed policy context.

Another key issue is considered to be the conflict in timescales - the apparent misalignment between political timescales and long-term climate change, coupled with a consistent underestimation of how big the climate challenge is, has resulted in a worrying deferment of responding to the evidence base, with potentially serious repercussion in the longer term (PR7).

\begin{abstract}
"Climate change is a long-term phenomenon but it's a huge one and I think people are consistently under estimating how big a challenge we're facing and will consistently defer responding to what we're trying to say. (...) A lot of decisions need to be made now about infrastructure, like our food systems, like how energy is transported. (...) I think for political reasons a lot of these things just kept pushed into the long grass" (PR7)
\end{abstract}

This conflict between short-term political timescales and longer-term sustainability perspective also manifests where politically driven decisions were considered to be motivated by the need to be seen to be doing something, rather than an evidence-based need (PR5, PR10).

\begin{abstract}
"that political pressure to be seen to be doing something, to be seen to be saying something positive, and that's when they'll mobilise ministers to go, and you see them in their wellies walking round fields saying, "We're all very concerned. Sometimes that's not based on any evidence, it's just what Twitter is saying, what Facebook is saying, it's what the Daily Mail is saying." (PR5)
\end{abstract}

\title{
6 Discussion
}

Reflecting on the above interview findings, there is a need to critically unpack whether the dynamism described earlier in the paper regarding the way innovative institutionality can emerge as a response to crises of climate adaptation and resilience is mirrored in attitudes from interviewees towards the development of equally dynamic local evidence bases. Our findings suggest that, while multi-actor institutions can crystallise and evolve as part of place-based responsiveness, it is equally important to appreciate the need for a dynamic approach to evidence procurement and application in responding to constantly shifting resilience-based challenges. Resisting the notion of 'place-agnostic' expertise and instead recognising the always situated and tacit nature of expert judgement could help enhance the effectiveness of local resilience strategies (Allen 2007).

The evolving discipline of 'translational science' (Chapin 2017; Schwartz et al. 2017) has identified climate change research, as an area where attention to co-production will play an increasingly powerful role in translating scientific 'evidence' into embodied decision-making practices (Wall et al. 2017). This helps shine conceptual light on some of our findings regarding the challenges involved in the co-production of evidence and a perception of situated 
judgements as appropriate forms of knowledge and expertise. One of the ways in which Translational Science seeks to overcome this is through a motion away from abstract notions of 'local' contexts requiring pre-packaged 'solutions' and towards a more relational understanding of place and of place-based partnerships (Safford et al. 2017).

Severing the attachment of judgement-based decisions from any political ideologies, placedriven collaborative approaches can help transform an uncertainty identified in the above findings over who is responsible for producing 'viable' evidence, into a more fundamental (and pressing) question of how to unite different perspectives. In particularly visceral fashion, empowering placebased adaptation strategies can facilitate the co-production of resilience strategies by orientating various stakeholders from different backgrounds towards the vulnerability of their shared locations, including the institutions in which they are culturally and vocationally embedded.

\section{Conclusions}

When it comes to decision-making relating to UK climate risks, results from our interviews have shown that a range of evidence types and sources are used and produced to support these processes at different scales. Due to the collaborative nature of managing and responding to climate risks such as heatwaves or flooding, a significant proportion of information is shared with partner organisations, other agencies or bodies. While a significant amount of evidence is considered to be available and is progressing in terms of adequacy and usefulness, there remain many barriers to the effective gathering of evidence for more robust assessment of current and future climate risks.

Several barriers are considered to limit the usefulness of existing evidence to inform decisionmaking including inaccessibility and data-sharing issues, lack of technical capacity to utilise existing data, disconnect between evidence producers and users, and difficulties in operationalising evidence in decision-making. Building the evidence base is compounded by several challenges such as inherent difficulties associated with trying to forecast or predict the (uncertain) future or in producing evidence on impacts due to missing information, and climate impacts changing and evolving over time. All of these require flexible mechanisms to adapt to the evolving context and continue to inform decision-making processes for climate resilience. With this in mind, interview findings suggest that efforts to address these evidence gaps should focus on (i) social and economic data, including data on vulnerable people and their exposure to risks, behavioural aspects of responses, and socio-economic assessments; (ii) assessment of policy mechanisms and other interventions which utilise evidence and inform decision-making; (iii) scientific and modelling evidence aligned with decision-maker needs; (iv) geographic or spatial data to better capture meteorological and climatological risks as they evolve; (v) local and real-time evidence capturing processes and impacts on the ground; and (vi) more effective communication of evidence translatable and transferable across scales and decision-makers.

Previous work has highlighted how the 2017 UK CCRA Evidence Report needed to be more operational in how it guides local adaptation policy by extending its reach beyond governmental agencies and institutions and working co-productively with local communities (Howarth et al. 2018). In reflecting on the findings overall, such inclusivity is paramount to promote more robust evidence-based local climate adaptation strategies where different approaches are needed for identifying risks and how these various risks heterogeneously affect different decision-makers in temporal and spatially nuanced ways. Hence, there is a need for evidence gathering and its communication to decision-makers to move beyond the reductionism of defining risk in terms of the socio-economic, physical, and biological to include social, political, and behavioural dimensions. 
Only then will evidence for greater climate resilience be truly robust and will align scales of policy governance that includes all decision-makers working in the scientific, practitioner, public, and community sectors.

Acknowledgements Our thanks are extended to theparticipants interviewed for this research, as well as to the anonymous reviewers whose comments helped shape the final version of this paper.

Funding information The authors gratefully acknowledge the financial support from the UK Economic and Social Research Council through the ESRC Nexus Network (Ref. ES/L01632X/1 and G1334-37) and the PlaceBased Climate Action Network (P-CAN) (Ref. ES/S008381/1).

Open Access This article is licensed under a Creative Commons Attribution 4.0 International License, which permits use, sharing, adaptation, distribution and reproduction in any medium or format, as long as you give appropriate credit to the original author(s) and the source, provide a link to the Creative Commons licence, and indicate if changes were made. The images or other third party material in this article are included in the article's Creative Commons licence, unless indicated otherwise in a credit line to the material. If material is not included in the article's Creative Commons licence and your intended use is not permitted by statutory regulation or exceeds the permitted use, you will need to obtain permission directly from the copyright holder. To view a copy of this licence, visit http://creativecommons.org/licenses/by/4.0/.

\section{References}

Adger WN, Dessai S, Goulden M et al (2009) Are there social limits to adaptation to climate change? Clim Chang 93(3-4):335-354. https://doi.org/10.1007/s10584-008-9520-z

Allen BL (2007) Environmental justice and expert knowledge in the wake of a disaster. Soc Stud Sci 37(1):103110. https://doi.org/10.1177/0306312706069431

ASC (2016) UK climate change risk assessment 2017 evidence report - summary for England. Adaptation SubCommittee of the Committee on Climate Change, London

Benzie M (2014) Social justice and adaptation in the UK. Ecol Soc 19(1):39

Cabinet Office (2011) National Strategic Framework for community resilience. Cabinet Office, London

Cash DW, Clark W, Alcock F et al (2002) Salience, credibility, legitimacy and boundaries: linking research, assessment and decision-making. KSG working paper series RWP02-046, Harvard University

Chapin FS (2017) Now is the time for translational ecology. Front Ecol Environ 15(10):539-539

Committee on Climate Change (2014) UK climate change risk assessment evidence report 2016 method document, version 1.0. Committee on Climate Change, London

Committee on Climate Change (2016) UK climate change risk assessment 2017 synthesis report: priorities for the next five years. Accessed: https://www.theccc.org.uk/wp-content/uploads/2016/07/UK-CCRA-2017Synthesis-Report-Committee-on-Climate-Change.pdf

Committee on Climate Change (2019) Progress in preparing for climate change - 2019 Progress Report to Parliament. Accessed: https://www.theccc.org.uk/publication/progress-in-preparing-for-climate-change2019-progress-report-to-parliament/

Corfee-Morlot J, Cochran I, Hallegatte S et al (2011) Multilevel risk governance and urban adaptation policy. Clim Chang 104:169-197. https://doi.org/10.1007/s10584-010-9980-9

Cutter SJ (2016) Resilience to what? Resilience for whom? Geogr J 182(2):110-113

De Ridder K, Maihen B, Lauwaet D et al (2017) Urban heat island intensification during hot spells - the case of Paris during the summer of 2003. Urban Sci 1(1). https://doi.org/10.3390/urbansci1010003

Defra (2013) UK National Adaptation Programme. Department of Food, Rural Affairs and Agriculture, London

DFID (2011) Defining disaster resilience: a DFID approach paper. Department for International Development, London

Di Gregorio M, Fatorelli L et al (2019) Multi-level governance and power in climate change policy networks. Glob Environ Chang. https://doi.org/10.1016/j.gloenvcha.2018.10.003

Duit A, Galaz V (2008) Governance and complexity - emerging issues for governance theory. Governance 21(3):311-335

Estrada F, Botzen W, Tol R (2017) A global economic assessment of city policies to reduce climate change impacts. Nat Clim Chang 7:403-406. https://doi.org/10.1038/nclimate3301 
Feola G, Nunes R (2014) Success and failure of grassroots innovations for addressing climate change: the case of the transition movement. Glob Environ Chang 24(1):232-250

Forrest S, Trell EM, Woltjer J (2017) Flood groups in England: governance arrangements and contribution to flood resilience. In: Trell E-M, Restemeyer B, Bakema M, Van Hoven B (eds) Governing for Resilience in Vulnerable Places. Routledge, London

Gersonius B, Ashley A, Pathirana A, Zevenbergen C (2015) Climate change uncertainty; building flexibility into water and flood infrastructure. Clim Chang 116:411-423

Gottschick M (2015) How stakeholders handle uncertainty in a local climate adaptation governance network. Clim Chang 132:445-457. https://doi.org/10.1007/s10584-014-1203-3

Gramberger M, Zellmer K, Kok K et al (2015) Stakeholder integrated research (STIR): a new approach tested in climate change adaptation research. Clim Chang 128:201-214. https://doi.org/10.1007/s10584-014-1225-X

Harley TA (2003) Nice weather for the time of year. The British obsession with the weather. In: Strauss A, Orlove BS (eds) Weather, Climate Culture, London, Berg pp 203-118

Harrington LJ, Otto FEL (2018) Changing population dynamics and uneven temperature emergence combine to exacerbate regional exposure to heat extremes under $1.5^{\circ} \mathrm{C}$ and $2{ }^{\circ} \mathrm{C}$ of warming. Environ Res Lett $13(3)$. https://doi.org/10.1088/1748-9326/aaaa99

Heidrich O, Dawson RJ, Reckien D et al (2013) Assessment of the climate preparedness of 30 urban areas in the UK. Clim Chang 120:771-784. https://doi.org/10.1007/s10584-013-0846-9

Heilig GK (2012) World urbanization prospects: the 2011 revision. United Nations, Department of Economic and Social Affairs (DESA), Population Division, New York

Howarth C, Monasterolo I (2016) Understanding barriers to decision making in the UK energy-food-water nexus: the added value of interdisciplinary approaches. Environ Sci Policy 61:53-60

Howarth C, Painter J (2016) The IPCC and local decision making on climate change: a robust science-policy interface? Palgrave Commun 2:16058. https://doi.org/10.1057/palcomms.2016.58

Howarth C, Viner D, Dessai S et al (2017) Co-producing climate change knowledge: incorporating practitioner evidence in the IPCC WGII process. Clim Serv 5:3-10

Howarth C, Morse-Jones S, Brooks K, Kythreotis A (2018) Co-producing UK climate change adaptation policy: an analysis of the 2012 and 2017 UK climate change risk assessments. Environ Sci Policy 89:412-420

Howarth C, Kantenbacher J, Guida K et al (2019) Improving resilience to hot weather in the UK: the role of communication, behaviour and social insights in policy interventions. Environ Sci Policy 94:258-261

IPCC (2018) Summary for urban policymakers - what the IPCC special report on global warming of $1.5^{\circ} \mathrm{C}$ means for cities. https://doi.org/10.24943/SCPM.2018

Johnson N, McGuinness M (2016) Flood resilience in the context of shifting patterns of risk, Complexity and Governance: An Exploratory Case Study. E3S FLOODrisk 2016, 3rd European Conference on Flood Risk Management. Lyon, France, 17-21 October 2016

King M (2014) Volunteering impacts. The Conservation Volunteers, London

Kythreotis AP, Bristow G (2017) The 'resilience trap': exploring the practical utility of resilience for climate change adaptation in UK city-regions. Reg Stud. https://doi.org/10.1080/00343404.2016.1200719

Kythreotis AP, Mantyka-Pringle CS, Mercer TG et al (2019) Citizen social science for more integrative and effective climate action: a science-policy perspective. Front Environ Sci. https://doi.org/10.3389/fenvs.2019.00010

Kythreotis AP, Jonas AEG, Howarth C (2020) Locating climate adaptation in urban and regional studies. Reg Stud 54(4):576-588. https://doi.org/10.1080/00343404.2019.1678744

Lövbrand E (2011) Co-producing European climate science and policy: a cautionary note on the making of useful knowledge. Sci Public Policy 38:225-236

Matyas D, Pelling M (2012) Disaster vulnerability and resilience: theory, modelling and prospective. Government Office of Science, London

Nash N, Whitmarsh L, Capstick S et al (2019) Local climate change cultures: climate-relevant discursive practices in three emerging economies. Clim Chang. https://doi.org/10.1007/s10584-019-02477-8

Nkiaka E, Taylor A, Dougill AJ et al (2019) Identifying user needs for weather and climate services to enhance resilience to climate shocks in sub-Saharan Africa. Environ Res Lett 14(12):123003

OECD (2013) What does "resilience" mean for donors? An OECD Factsheet

Pelling M (2011) Adaptation to climate change: from resilience to transformation. Routledge, UK

Pelling M, Dill K (2010) Disaster politics: tipping points for change in the adaption of socio-political regimes. Prog Hum Geogr 34(1):21-37

Pitt M (2007) Learning lessons from the 2007 floods: an independent review. Cabinet Office, London

Preston I, Banks N, Hargreaves K et al (2014) Climate change and social justice: an evidence review. Joseph Rowntree Foundation, York

Safford HD et al (2017) Linking knowledge to action: the role of boundary spanners in translating ecology. Front Ecol Environ 15(10):560-568

Schwartz MW et al (2017) Developing a translational ecology workforce. Front Ecol Environ 15(10):587-596 
Sharma V, Orindi V, Hesse C et al (2014) Supporting local climate adaptation planning and implementation through local governance and decentralised finance provision. Dev Pract 24(4):579-590. https://doi. org/10.1080/09614524.2014.907240

Shepherd TG, Boyd E, Calel RA et al (2018) Storylines: an alternative approach to representing uncertainty in physical aspects of climate change. Clim Chang 151:555-571. https://doi.org/10.1007/s10584-018-2317-9

Skougaard Kaspersen P, Halsnæs K (2017) Integrated climate change risk assessment: a practical application for urban flooding during extreme precipitation. Clim Serv. https://doi.org/10.1016/j.cliser.2017.06.012

Steentjes K, Demski C, Seabrook A et al (2020) British public perceptions of climate risk, adaptation options and resilience (RESiL RISK): topline findings of a GB survey conducted in October 2019. Cardiff University, Cardiff

Thompson E, Frigg R, Helgeson C (2016) Expert judgment for climate change adaptation. Philos Sci 83(5): 1110-1121. https://doi.org/10.1086/687942

Twigger-Ross C, Brooks K, Papadopoulou L, Orr P (2015) Community resilience to climate change: an evidence review. Joseph Rowntree Foundation, York

UNSDR (2015) Hyogo framework for action 2005-2015: ISDR international strategy for disaster reduction. World conference on disaster reduction January 2005, Japan

Wall TU, McNie E, Garfin GM (2017) Use-inspired science: making science usable by and useful to decision makers. Front Ecol Environ 15(10):551-559

Waters J, Adger WN (2017) Spatial, network and temporal dimensions of the determinants of adaptive capacity in poor urban areas. Global Env Change. https://doi.org/10.1016/j.gloenvcha.2017.06.011

White R, Stirling A (2012) Sustaining trajectories towards sustainability: dynamics and diversity in UK communal growing activities. Glob Environ Chang 23:838-846

Williams L Erens B Ettelt S et al (2020). Evaluation of the Heatwave Plan for England: Final report. London: PIRU publication. Accessed 14/06/2020. https://piru.ac.uk/assets/files/EvaluationoftheHeatwavePlanforEnglandFinalReport.pdf

Young JC, Rose DC, Mumby HS et al (2018) A methodological guide to using and reporting on interviews in conservation science research. Methods Ecol Evol. https://doi.org/10.1111/2041-210X.12828

Zhou B, Rybski D, Kropp JP (2017) The role of city size and urban form in the surface urban heat island. Nat Sci Rep 7(4791). https://doi.org/10.1038/s41598-017-04242-2

Publisher's note Springer Nature remains neutral with regard to jurisdictional claims in published maps and institutional affiliations.

\section{Affiliations}

\section{Candice Howarth $^{1} \cdot$ Sian Morse-Jones ${ }^{2} \cdot$ Andrew Kythreotis $^{3,4,5} \cdot$ Katya Brooks $^{6} \cdot$ Matt $^{2}$ Lane $^{7}$}

1 Grantham Research Institute on Climate Change and the Environment, London School of Economics and Political Sciences, London, UK

2 Collingwood Environmental Planning, 50 Westminster Bridge Road, London, UK

3 School of Geography and Lincoln Centre for Water and Planetary Health, University of Lincoln, Lincoln, UK

4 Tyndall Centre for Climate Change Research, University of East Anglia, Norwich, UK

5 School of Psychology, Cardiff University, Cardiff, UK

6 Faculty of Arts and Social Sciences, University of Surrey, Guildford, UK

7 School of Geosciences, University of Edinburgh, Edinburgh, UK 